\title{
O impacto da colonização europeia na alimentação e o papel da mulher indígena na conservação do patrimônio alimentar
}

\author{
The impact of European colonization on food and the role of indigenous women in food heritage \\ conservation
}

\author{
Vandreza Amante Gabriel ${ }^{1}$ \\ Marilda Checcucci Gonçalves da Silva
}

\begin{abstract}
Resumo
O artigo apresenta resultados de pesquisa sobre mudanças ocorridas no sistema alimentar dos Mbyá-guarani em decorrência do impacto da colonização europeia sobre esse sistema, abordando as consequências para as crianças Mbyá e o importante papel desempenhado pela mulher na continuidade do patrimônio alimentar tradicional, enquanto uma forma de resistência às situações daí decorrentes. Para tanto realizou-se uma pesquisa, servindo-se do método etnográfico, no tekoá vy'a em Major Gercino, Vale do Rio Tijucas, Santa Catarina, Brasil. Neste artigo serão abordadas algumas questões que envolvem o processo de colonização e o papel da mulher indígena. A resistência dos Mbyá-Guarani face às pressões que vem sofrendo com este processo em seu sistema alimentar (SILVA, 2008) tem revelado que o grupo Mbyá pesquisado tem lutado por conservar esse sistema, através de várias estratégias, permanecendo até os dias atuais elementos dos hábitos tradicionais relacionados ao seu sistema alimentar tradicional, à alimentação e a cosmologia que envolve essas práticas. Há constantes mudanças em decorrência do processo de colonização e da relação que lhes é imposta com efeito sob a terra e o território. Esse aspecto aponta para a questão do desenvolvimento no território, evidenciando as consequências danosas que um tipo de desenvolvimento voltado para o crescimento econômico pode ocasionar ao desalojar grupos humanos que tradicionalmente garantiam a sua subsistência de forma satisfatória e em harmonia com o meio ambiente de suas terras tradicionais.
\end{abstract}

Palavras-Chave: Colonização Europeia. Sistema Alimentar Mbyá-Guarani. Papel das Mulheres. Alimentação Infantil. Estratégias de Resistência.

\begin{abstract}
This article presents research results on changes in the Mbyá-Guarani food system due to the impact of European colonization on this system, addressing the consequences for Mbyá children and the important role played by women in the continuity of traditional food heritage, as a form of resistance to the resulting situations. For that, a research was done, using the ethnographic method, in the tekoá vy'a in Major Gercino, Tijucas River Valley, Santa Catarina, Brazil. This article will address some issues that involve the colonization process and the indigenous women's role. The resistance of the Mbyá-Guarani to the pressures that have been suffering from this process in their
\end{abstract}

\footnotetext{
${ }^{1}$ Doutoranda do Programa de Pós-Graduação em Desenvolvimento Regional - PPGDR da Universidade Regional de Blumenau. Bolsista Demanda Social. O presente trabalho foi realizado com apoio do Auxílio Furb e da Coordenação de Aperfeiçoamento de Pessoal de Nível Superior - Brasil (CAPES) - Código de Financiamento 001, Portaria No 206, de 4 de setembro de 2018. E-mail: van_ag@ hotmail.com

2 Doutora em Educação (UNICAMP). Docente do Programa de Pós-Graduação em Desenvolvimento Regional PPGDR da Universidade Regional de Blumenau - FURB. E-mail: marildacheccucci@ hotmail.com
} 
food system (SILVA, 2008) has revealed that the Mbyá group researched has been struggling to conserve this system, through several strategies, remaining to this day elements of the traditional habits related to their food system, nourishment and the cosmology that involves these practices. There are constant changes because of the colonization process and the relationship that is imposed on them under the land and the territory. This aspect points to the issue of development in the territory, highlighting the harmful consequences that a type of development geared towards economic growth can lead to the displacement of human groups that traditionally guarantee their subsistence in a satisfactory way and in harmony with the environment of their traditional lands.

Keywords: European Colonization. Mbyá-Guarani Food System. Women's Role. Infant Feeding. Resistance Strategies.

\section{Introdução}

Tradicionalmente os grupos Guarani que compreendem os Ñandeva, Kaiowá e Mbyá habitavam um vasto território entre o Uruguai, Argentina, Paraguai, Bolívia, Rio Grande do Sul, Santa Catarina, Paraná, Mato Grosso do Sul, São Paulo, Rio de Janeiro e Espírito Santo. Atualmente, encontram-se confinados em pequenas ilhas com algumas aldeias sem a devida demarcação regularizada pelo Estado (BRIGHENTI, 2012; LADEIRA, 2008) ${ }^{3}$. Um destes grupos, o Mbyá-Guarani, foi obrigado a modificar drasticamente seu modo de vida e sua relação com o território e em consequência disso seu sistema alimentar (SILVA, 2008). Os sistemas alimentares dos povos originários passaram por adaptações e ressignificações ao longo do tempo desde o início da colonização europeia no Sul do Brasil e das relações interétnicas estabelecidas no novo contexto de contato com a população branca no território.

Desde o início da colonização podemos acompanhar os relatos documentados da grande devastação e exploração predatória que o território brasileiro vem sofrendo para subsidiar o desenvolvimento dos países que detém o poder da economia mundial. As terras para a formação do Brasil, em grande parte, foram ocupadas desconsiderando-se as especificidades dos povos originários e das populações tradicionais. Há mais de 500 anos podemos rever a exportação de madeira, pedras preciosas, plantas medicinais, animais silvestres ${ }^{4}$, minérios, alimentos e outras matérias-primas que até hoje estão sendo exportadas e transformadas. Muitos desses lugares são ilhas em meio à agricultura convencional que utiliza pesticidas e agrotóxicos na lavoura. Os indígenas em geral não utilizam esses insumos, nem mesmo sementes transgênicas. Esses aspectos convergem para a sua importância na preservação desses ecossistemas (TEMPASS, 2010).

\footnotetext{
${ }^{3}$ Grupos Guarani são encontrados em áreas remanescentes de Mata Atlântica, inclusive no Pará.

${ }^{4}$ Um exemplo é a venda de perdizes para consumo nas feiras de Goiás, Minas Gerais, restaurantes de São Paulo e Rio de janeiro e a exportação para os Estados Unidos e Europa (FERRARO, 2016). Para a identificação de aves comestíveis ver o livro de Emilio Goeldi “As Aves do Brasil”, de 1894.
} 
Litaiff e Darella (2000) em “Os índios Guarani Mbyá e o Parque Estadual da Serra do Tabuleiro" discutem as questões que permeiam o uso comum da terra, pois o grupo que atualmente está no tekoá vy'a habitou anteriormente o tekoá Itaty no Morro dos Cavalos, município de Palhoça (SC). Foram 20 anos de negociação com o governo para que, por indenização pela duplicação da BR-101 trecho Palhoça (SC) até Osório (RS) ocupassem a partir de 2009, uma área adequada para a continuidade de suas práticas tradicionais (DARELLA; GARLET; ASSIS, 2000). Outras famílias aguardam indenizações desse projeto realizado pelo Estado brasileiro. Foram 30 aldeias de diferentes grupos impactadas pela obra de duplicação da BR-101 no trecho citado. Para Ladeira (2008, p.110), em tese intitulada "Espaço geográfico Mbyá-Guarani: significação, constituição e uso", "incontáveis são as situações em que os Guarani se vêm surpreendidos por ações que afetam o seu território. E, em todas elas, as condições de enfrentamento são desiguais”. Segundo Ladeira (2008, p. 109) "em um mundo desfigurado pelas ações humanas (nos últimos 30 anos, o processo de desfiguração do litoral, como um todo, é intenso), a seletividade Guarani também se vê tolhida, e as alternativas têm que se concentrar nas poucas áreas naturais 'disponíveis' de Mata Atlântica”. O território Guarani é marcado por muitas histórias imemoriais que orientam a cosmologia do grupo, sua visão cosmopolítica e social com a natureza (MENDES, 2015; TEMPASS, 2010; VIVEIROS DE CASTRO, 1990).

A pesquisa se justifica por permitir compreender quais as mudanças que estão afetando a alimentação das crianças Mbyá, visto a importância da alimentação nessa fase da vida e os problemas daí advindos, que passam pela questão muitas vezes da falta de alimentos ou de uma alimentação inadequada em relação à sua tradição, pela própria desconsideração do Estado para com essa questão através da distribuição de cestas básicas e de merenda escolar que não consideram as especificidades da alimentação do grupo, o que vem levando à desnutrição, obesidade e diabetes no próprio meio infantil. Grande parte do grupo Mbyá-Guarani que vive atualmente no Brasil se identifica e dependeu sempre de recursos advindos dos alimentos remanescentes de Mata Atlântica.

\section{Metodologia}

Para responder aos objetivos de pesquisa recorreu-se ao método etnográfico alicerçado na pesquisa de campo com visitas esporádicas em número de 50 entre os anos de 2016 e 2018 no tekoá vy’a Mbyá-Guarani em Major Gercino (SC). Em campo recorreu-se ao uso de várias técnicas de 
pesquisa, tais como observações, fotografias, entrevistas, análise de notícias de jornais, mapas e recursos audiovisuais para o levantamento de dados, cruzando-se os resultados com a bibliografia existente sobre o grupo. Os principais interlocutores de maneira mais sistemática foram o cacique e pagé Artur Benite, 76 anos, conhecido em Guarani por werá mirim, sua esposa Maria Campos ,49 anos, pará retê, duas das filhas de Seu Artur, Irma Benite, 42 anos, kerexue, Cláudia Benite, 36 anos, pará mirim, seu esposo Augustinho Moreira, 36 anos, werá tukumbó, Márcia Ramires, 38 anos, pará mirim e suas filhas, Maura Ramires, 26 anos, kerexu, Andrea Ramires Benite, 18 anos, pará mirim e Letícia Ramires Benite, 10 anos, ará, embora a relação com o grupo tenha abarcado um universo maior. O diário de campo foi uma peça fundamental no processo de pesquisa embasando a fundamentação teórica sobre a organização do grupo, as práticas culturais vivenciadas e as relações estabelecidas com a sociedade envolvente com o aporte da memória oral documentada em entrevistas e o registro do local adensado com a produção de imagens do grupo Mbyá-Guarani. Recorreu-se em especial aos idosos, mulheres e crianças para se identificar através da memória as diferenças alimentares nas diferentes gerações. A seguir apresentaremos uma pequena reflexão sobre algumas questões relacionadas aos saberes femininos e a culinária indígena Mbyá-Guarani, em seguida abordaremos o consequente papel da mulher no território marcado pela colonização e pontos que interligam o desenvolvimento de grupos indígenas ao etnodesenvolvimento. Nas considerações finais apresentaremos os resultados parciais de pesquisa que vem sendo realizada no doutorado do Pós-Graduação em Desenvolvimento Regional da FURB sob orientação da professora e pesquisadora Marilda Checcucci Gonçalves da Silva.

\section{Os saberes femininos e a culinária indígena Mbyá-Guarani}

No caso Mbyá-Guarani do tekoá vy’a a prática diária da alimentação denominada por eles como "tradicional" inclui a plantação de sementes herdadas de parentes, a observação da influência da lua na agricultura praticada, a não utilização de insumos químicos, a prática de coleta na mata e o reconhecimento do papel da biodiversidade. Estas são essenciais para a continuidade dos saberes femininos, inclusive àqueles ligados à culinária (TEMPASS, 2010). São as mulheres que detém este saber que vem sendo repassado de uma geração a outra.

O papel do colonialismo ao retirar os indígenas de suas terras e de seu território, até confinálos em situação de "reservas" criando algumas "ilhas" com situações diferenciadas, tem alterado profundamente a alimentação dos grupos. Em muitas comunidades há restrições na alimentação dita 
por eles como "tradicional" por conta da falta de acesso à alimentos "naturais" como tubérculos locais, frutas, peixes e outros animais capturados na mata, em conseqüência do precário contexto agrícola em que se encontram por conta do tipo de terra a que têm acesso. Eles recebem eventualmente doações de alimentos em forma de "cesta básica" ou de alimentos industrializados. Observamos que atualmente muitos desses indígenas têm acesso à supermercados.

Uma questão importante a considerar no tema da alimentação indígena é a qualidade do alimento que é oferecido na merenda escolar e nas cestas básicas distribuídas à população indígena. “As críticas com relação à alimentação oferecida atualmente nas escolas indígenas em São Paulo são uma constante. Os educadores indígenas se queixam que há anos denunciam a situação sem que providências efetivas tenham sido tomadas para reverter esse quadro" (ANDRADE; BELLINGER, 2016, p. 30). A cartilha "Alimentação nas escolas indígenas: desafios para incorporar práticas e saberes" lançada pela Comissão Pró-Índio de São Paulo em 2016, afirma que "os resultados do I Inquérito Nacional de Alimentação e Saúde e Nutrição dos Povos Indígenas, divulgados em 2010, reforçaram as evidências de vulnerabilidade vivida por crianças e mulheres indígenas”. Segundo a cartilha, “a pesquisa, realizada entre 2008 e 2009, indicou que 83,2\% das aldeias investigadas sentiam falta de alimentos em alguma época do ano. Na região Sul/Sudeste, 77,8\% dos domicílios indígenas tinham as cestas básicas como uma das principais fontes de alimento" (ANDRADE; BELLINGER, 2016, p. 11). Segundo a cartilha o problema da soberania alimentar foi um tema trazido pelas mulheres Guarani. Elas chamaram atenção para o desafio que representava para homens e mulheres Guarani assegurarem sua alimentação. "A alimentação oferecida nas escolas atualmente não é composta de alimentos saudáveis nem tampouco respeita a cultura alimentar dos povos indígenas" (ANDRADE; BELLINGER, 2016, p. 07). Com a inserção do sal e do açúcar na dieta alimentar doenças como desnutrição e diabetes se tornaram realidade nas comunidades afetando a saúde das crianças. Tradicionalmente essas enfermidades não existiam porque os alimentos Mbyá-Guarani eram “naturais”, não industrializados, sendo que o sal e açúcar não faziam parte da dieta e os alimentos não recebiam pesticidas.

Recentemente o Programa Nacional de Alimentação Escolar (Pnae), incluiu a comercialização da produção rural indígena da Terra Indígena Rio Branco em Itanhaém (SP) para a merenda escolar adquirida pelo Selo da Identificação da Participação da Agricultura Familiar (Sipaf). Essa iniciativa é importante por se tratar de um passo inicial para o reconhecimento da diversidade alimentar dos grupos indígenas e a importância de preservarem as suas práticas agrícolas voltadas para a subsistência. O projeto decorre da demanda indígena e dos esforços em 
rede da Funai e da Secretaria Municipal de Educação (Banco de Alimentos/ Departamento de Merenda Escolar) (FUNAI, 2017).

A alimentação na escola chamada nhembo'ea vy'a atualmente além de carne de frango e carne bovina industrializada, inclui na merenda escolar a farinha de trigo, mandioca e milho, batata doce, repolho, cebola, tomate, cenoura, beterraba, macarrão, arroz e feijão, sendo que muitos destes produtos foram incorporados a partir dos novos hábitos alimentares adquiridos depois do contato. Em 2017 a escola ficou sem receber os alimentos da merenda escolar por alguns meses. No final do ano o responsável pela comunidade recebeu um cartão para compra de carne para a escola. No tekoá vy’a, Irma Benite conhecida como kerexu, é merendeira e estava de licença devido a ter um filho recém-nascido. A escola passa por um período de transição estrutural aguardando a reforma e as crianças se alimentaram na casa de Cláudia Benite, pará mirim, que concordou em cozinhar a merenda, pois ela já possuía experiência como merendeira da escola indígena do Morro dos Cavalos, em Palhoça (SC) onde conheceu alguns temperos, legumes e verduras que não faziam parte da culinária tradicional e foram incorporados à culinária do grupo, como salada de alface, tomate e cebola temperada com vinagre.

A situação diferenciada que encontramos no grupo que pesquisamos no tekoá vy’a se dá por conta de ter tido a possibilidade de acesso a uma terra "saudável”, fértil, área de mata, água potável se comparada à situação anterior, onde se encontravam, no Morro dos Cavalos, Palhoça (SC). No ano de 2009 treze famílias se mudaram do Morro dos Cavalos para a área rural de Major Gercino (SC), espaço de 149 hectares que atualmente abriga vinte e sete famílias num total de 120 pessoas. Alguns moradores são beneficiários do Bolsa Família, há agente de saúde, pessoas aposentadas e a maioria sobrevive da venda de artesanato no centro de cidades vizinhas e de trabalhos sazonais como a colheita de alimentos em outras terras.

$\mathrm{Na}$ comunidade existem hortas contendo salsinha, cebolinha, repolho, alface, cenoura, alimentos que não fazem parte da dieta "tradicional" do grupo. Algumas sementes vieram da agropecuária, mas outras eles guardam de seus antepassados, como o milho. Essa população criou estratégias distintas de adaptação ao local por conta da sua situação atual em relação à terra, em consequência do contato com a sociedade envolvente, estabelecendo uma nova relação com o território. Em função dessa nova situação eles estão buscando retomar o cultivo das espécies antigas ligadas à sua tradição alimentar. Atualmente eles possuem criação de animais como algumas espécies de galinhas, pato, porco branco, plantam milho, feijão, moranga, batata-doce, mandioca, cana-de-açúcar, palmito, melancia, abacaxi, abacate, amora, banana, mamão, amendoim, maracujá, 
jabuticaba, laranja, pitanga, limão, utilizam mel e plantas medicinais. Um dos alimentos principais da dieta Guarani é o milho dito por eles como avaxí que pode ser consumido assado, cozido, como farinha ou transformado em pamonha, canjica, sucos e pães.

Uma das interlocutoras da pesquisa pará mirim Márcia Ramires 38 anos, cresceu em uma aldeia indígena nas redondezas da cidade de Joinville, mas nasceu na aldeia Canta Galo no Rio Grande do Sul. Pergunto se na casa dos pais se comia arroz com feijão ou macarrão tal como se come hoje e ela me responde: "Não vi não. Eu vi só quando eu fui vender artesanato e às vezes convidavam para a gente almoçar. Aí deram para a gente comer. Na casa não”. Se referindo a tempos mais antigos ela comenta que "nessa época que meus avós comem mais era só aipim, batata, milho. Só essas coisas. E carne de caça. Misturava com mandioca, carne, a caça”. Pará mirim Márcia Ramires conta que na casa de sua mãe não se ganhava cesta básica e não comiam o macarrão, habito criado posteriormente em parte com a introdução da cesta básica. Ela fala que em tempos antigos não havia energia elétrica na casa "a casa era que nem daquela $o p y^{5}$ de barro. Comprava velas e fazia lampião. Sempre morava junto minha mãe e meus avós, são três, quatro famílias. Era tudo parente”. Ela conta que naquela época nunca utilizaram o remédio da farmácia e que sempre utilizaram remédio da mata. A entrevista foi realizada em agosto de 2018 no tekoá vy'a em Major Gercino (SC).

Tais como nessas passagens as memórias sobre a família revelam e identificam o processo de mudança dos hábitos alimentares a partir do contato com o branco. Ainda assim os modos de fazer repassados de uma geração para outra dão sentido aos hábitos cotidianos e conformam a identidade cultural das mulheres do grupo Mbyá-Guarani, que mantêm vários hábitos e modos de fazer ligados à alimentação e culinária tradicional e parecem disso ter orgulho.

Em relação à maneira como processam e cozinham os alimentos as famílias Mbyá-Guarani pesquisadas fazem vários tipos de fogueira no chão, para cozinharem e mesmo "assarem" os alimentos, servindo-se além de madeiras e pedras, de tudo aquilo que pode ajudar nesse processo como a grade de uma geladeira. Além disso utilizam o fogão à lenha e a gás. Utilizam-se de diferentes técnicas para cozinhar resultando em diferentes comidas e sabores com uma diversidade nos modos de fazer, dos tempos de preparo, tanto comidas assadas, cozidas ou fritas. Há preferência pela fogueira dita por eles como "tradicional", feita no chão. Todo este cotidiano, universo repleto de signos e sentidos, permeia a vida das mulheres que desde a infância compartilham de um saber fazer cotidiano que formam a identidade Mbyá-Guarani. É já na primeira infância que as mulheres

\footnotetext{
${ }^{5}$ Casa de reza feita de maneira tradicional com barro, uma armação de madeira e um trançado de palha como telhando.
} 
observam suas irmãs, primas, tias e mães cozinhando, vivendo a aldeia e decidindo sobre o seu futuro. Essas memórias acompanham a menina desde a infância até a fase adulta quando se dedicarão à maternidade, já na adolescência, para eles o início da fase adulta ${ }^{6}$. Pelo que pude perceber é um momento em geral de satisfação para essas mulheres. A maternidade faz parte dessa identidade. Ela é parte de um momento decisivo na continuidade da tradição e permanência do grupo.

Scott (1995, p. 75) define o termo "gênero" como um meio de distinguir a prática sexual dos papéis sexuais atribuídos às mulheres e aos homens. Segundo Scott (1995, p. 89) "o gênero, então, fornece um meio de decodificar o significado e de compreender as complexas conexões entre várias formas de interação humana". Para a autora "o termo 'gênero' torna-se uma forma de indicar 'construções culturais' - a criação inteiramente social de ideias sobre os papéis adequados aos homens e às mulheres. Trata-se de uma forma de se referir às origens exclusivamente sociais das identidades subjetivas de homens e de mulheres”. Esclarece que “"gênero' é, segundo esta definição, uma categoria social imposta sobre um corpo sexuado" (SCOTT, 1995, p. 75) que, de maneira política, torna-se o centro das relações sociais (MAUSS, 2003). Observa-se que esses papéis no grupo indígena são definidos em função dos sexos dos indivíduos, identificando os papéis adequados a homens e mulheres, sendo a culinária um papel considerado essencialmente feminino.

\section{O papel das mulheres no território: algumas questões}

Para podermos discutir as questões relacionadas ao território e à América Latina Salomone (1996, p.147) acredita que devemos "hacer el intento de recuperar el pensamento de mujeres en América Latina necesariamente nos pone por delante la tarea de hacer um cuestionamiento de la tradición de estúdios" (SALOMONE, 1996, p. 147).

$\mathrm{Na}$ tradição acadêmica ou nas expressões populares e culturais as mulheres estão continuamente reafirmando seu papel perante as imposições sociais que transformam o seu cotidiano. Federici

\footnotetext{
${ }^{6}$ Segundo a Funai desde 1500 até a década de 1970 a população indígena brasileira decresceu acentuadamente e muitos povos foram extintos. O desaparecimento dos povos indígenas passou a ser visto como uma contingência histórica, algo a ser lamentado, porém inevitável. No entanto, este quadro começou a dar sinais de mudança nas últimas décadas do século passado. A partir de 1991, o IBGE incluiu os indígenas no censo demográfico nacional. O contingente de brasileiros que se considerava indígena cresceu $150 \%$ na década de 90 . O ritmo de crescimento foi quase seis vezes maior que o da população em geral. $\mathrm{O}$ percentual de indígenas em relação à população total brasileira saltou de $0,2 \%$ em 1991 para $0,4 \%$ em 2000, totalizando 734 mil pessoas. Houve um aumento anual de 10,8\% da população, a maior taxa de crescimento dentre todas as categorias, quando a média total de crescimento foi de 1,6\%. Disponível em <http://www.funai.gov.br > Acesso em 26/10/2014.
} 
(2017) apresenta dados de perseguições contra mulheres, chamadas bruxas, e casos comparativos entre América Latina e Europa com o objetivo de se compreender a possível relação entre esses continentes em um período de cercamento e privatização de terras, fortalecimento do Estado, a implementação do genocídio como política e a desvalorização dos saberes femininos. Esta obra traz relatos e referências essenciais para que possamos perceber a história de resistência dos grupos humanos à escravidão (moderna ou não). Na América Latina ou na Europa essas pessoas que viviam em terras de uso comum, com recursos naturais que se transformavam em moradia e alimentação, não aceitaram passivamente as mudanças impostas pelo poder da força (ou da forca). As mulheres perseguidas por conhecerem saberes ancestrais vivem até a atualidade uma herança forjada no conceito do masculino, da aceleração do tempo para que o ser humano seja consumido pelo trabalho no imperialismo econômico. A autora ressalta que essa desconsideração do feminino nos espaços individuais e coletivos não é suficiente para extrair por completo o papel social que está incumbido a elas. "Foram as mulheres que defenderam de forma mais ferrenha o antigo modo de existência, e que se opuseram com mais veemência a nova estrutura de poder — provavelmente devido ao fato de serem também as mais afetadas". A autora "mostra a existência de importantes divindades femininas nas religiões pré-colombianas, as mulheres tinham uma posição de poder nessas sociedades" (FEDERICI, 2017, p. 400). "Além de serem agricultoras, donas de casa, tecelãs e produtoras dos panos coloridos utilizados tanto na vida cotidiana quanto durante as cerimônias, também eram oleiras, herboristas, curandeiras e sacerdotisas a serviço dos deuses locais" (FEDERICI, 2017, p. 401).

No livro "La Resistência de los Guarani del Paraguay a la Conquista Española (1597-1556)" de Florencia Roulet (1993) o encontro dos grupos é descrito em cooperações e conflitos. No Capítulo 1 a autora descreve o roubo de mulheres indígenas por ela chamada de "saca de mujeres" (ROULET, 1993, p. 61-62). Segundo ela a expedição dos colonizadores espanhóis Pedro de Mendoza e Domingo Martínez de Irala em 1535 foi extremamente violenta. “Em la 'Relación' que Irala dejó em el puerto de Buenos Aires al despoblarlo em 10 de abril de 1541 se decía que los carios de Assunción habían dado a los españoles 700 mujeres 'para que los sirvan em sus casas y em roças'(en: GGV45/915:2)”. Ela afirma que um religioso, “quince años más tarde, el Clérigo Martín González hablaba de 40 mil índias em poder de los españoles” (ROULET, 1993, p. 61). No caso brasileiro, nos deparamos durante a pesquisa com histórias de mulheres "pegas no laço", muitas ainda quando crianças, por holandeses, espanhóis, portugueses, italianos e alemães no Pará, na Bahia, em São Paulo, no Vale do Itajaí e no sul de Santa Catarina. São memórias de família 
contadas na atualidade por homens e mulheres como parte da história social do grupo. Elas serviam como prisioneiras com trabalho escravo doméstico e sexual. Muitas morreram, outras fugiram, algumas prostituíram-se ou serviram de base reprodutora para a população regional disponibilizando mão de obra barata até os dias atuais.

O historiador John Manuel Monteiro (1989, p. 155), analisando a escravização de indígenas trazidos do "sertão" para São Paulo apresenta dados dizendo que "à primeira vista, o que se destaca nesta lista é a presença preponderante de mulheres e crianças, representando quase 70 por cento do total". Para ele "este fato refletia a divisão de trabalho adotada inicialmente pelos colonos nos seus estabelecimentos agrícolas, onde mulheres e, possivelmente, crianças executavam as funções ligadas ao plantio e à colheita”, "enquanto os homens prestavam serviços sobretudo no setor de transportes e na reprodução da população escrava por meio do apresamento". O autor comenta que muitas dessas pessoas capturadas eram batizadas e tinham padrinhos. "As crianças batizadas podem ser divididas nas seguintes categorias: filhos de pais índios, onde os dois pais são declarados; filhos de mãe índia e pai não declarado; e filhos ilegítimos de mãe índia e pai branco" (MONTEIRO, 1989, p. 163). O autor conclui que "as exigências da economia colonial, muitas vezes, alteram a divisão de trabalho a ponto de romper definitivamente padrões tradicionais de agricultura de subsistência. Embora muitas índias permanecessem no setor agrícola, os colonos preferiam empregar as mulheres no serviço doméstico" (MONTEIRO, 1989, p. 164-165). Podemos citar o "Bandeirantismo" e o ataque aos Guarani como forma de aprisionar pessoas para o trabalho na lavoura, uma forma de exploração capitalista do ser humano. Iniciava-se um processo de acumulação primitiva que culminaria no desenvolvimento desigual na atualidade nos processos de dependência econômica que tornaria o Brasil politicamente vinculado à escravidão (MONTEIRO, 1989).

Segundo Smith (2014, p. 201) “o projeto de prática de violência sexual nas colônias estabelece a ideologia de que os corpos indígenas são naturalmente violáveis - e, portanto, as terras indígenas também são naturalmente violáveis”. Com a reflexão sobre o imaginário social da época "a história da violência sexual e do genocídio contra as mulheres indígenas ilustra como a violência engendrada funciona, em geral, como uma ferramenta do racismo e do colonialismo entre as mulheres de cor". Para ela "enquanto os colonizadores faziam uso de violência sexual para eliminar as populações nativas, os proprietários de escravos utilizavam o estupro para reproduzir uma mão de obra explorável" (SMITH, 2014, p. 205). Segundo a autora, "na época das viagens de exploração de Colombo, a sociedade europeia era um sistema disfuncional, abalado por miséria generalizada, 
doenças, opressão religiosa, guerra, e violência institucionalizada" (SMITH, 2014, p. 206). “Além disso, as sociedades europeias eram completamente misóginas. O patriarcado cristão que estruturava a sociedade europeia era intrinsecamente violento" (SMITH, 2014, p. 207). A autora faz referência à violência nos grupos indígenas dizendo que "ao discutir tais tendências, convém não generalizar demais ou dar a impressão de que as comunidades indígenas eram utópicas antes da colonização. Certamente havia violência engendrada antes da colonização", mas "tanto os registros orais quanto escritos frequentemente mostram que ela é relativamente rara, assim como a severidade na punição para os perpetradores de violência" (SMITH, 2014, p. 209). Ela considera que "a demonização da mulher indígena pode ser vista como uma estratégia do homem branco para manter o controle sobre a mulher branca" (SMITH, 2014, p. 211).

Portanto, para colonizar um povo cuja sociedade não era hierárquica, os colonizadores deviam primeiro naturalizar a hierarquia através da instituição patriarcal. A violência patriarcal engendrada é o processo pelo qual os colonizadores inserem a hierarquia e a dominação no corpo dos colonizados. Ironicamente, enquanto escravizavam o corpo das mulheres, os colonizadores diziam que estavam, na verdade, libertando de alguma forma as indígenas da "opressão" a que elas supostamente estavam sujeitas nas nações indígenas (SMITH, 2014, p. 213).

A autora faz uma análise sobre a questão da violência contra as mulheres indígenas nos Estados Unidos, México e Guatemala e relaciona tais atos com projetos de colonização branca europeia, já que mulheres afro-americanas sofrem a mesma violência. Considera as propagandas ideológicas dos grupos de poder nas expressões cotidianas transmitidas pelas propagandas de televisão que se massificam no imaginário colonial. No Dossiê "Mulheres Indígenas" publicado pela Revista Estudos Feministas (1999) a antropóloga Cristiane Lasmar apresenta algumas representações sobre o contexto em que as mulheres indígenas estão inseridas e diz que "a concepção da humanidade degradada do indígena incidiu com bastante força sobre o elemento feminino" (LASMAR, 1999, p. 146). A autora explica que "por outro lado, fatores da própria estrutura social e cultura das sociedades indígenas sul-americanas podem ter concorrido para encorajar o privilégio analítico da perspectiva masculina por parte dos pesquisadores" (LASMAR, 1999, p. 147). Segundo ela, “a pregnância implícita ou explícita da problemática da dominação concorreu para tornar menos acessível o ponto de vista das próprias mulheres indígenas sobre os processos sociais envolvidos na constituição das relações entre os gêneros, mas a recusa do idioma da desigualdade não é suficiente para que a voz feminina seja ouvida" (LASMAR, 1999, p. 154). 
Para a autora "garantir-lhes visibilidade é, certamente, a única forma de combater os efeitos das representações estereotipadas" (LASMAR, 1999, p. 154).

Souza (2018) em seu artigo discute como as mulheres indígenas são representadas nos Relatório Figueiredo e no Relatório Final da Comissão Nacional da Verdade, documentos que revelam as relações estabelecidas durante a ditadura militar no Brasil na década de 1960. O texto faz parte do Dossiê "Povos indígenas e as Ditaduras na América Latina" da Revista Espaço Ameríndio. Segundo a autora "a discussão sobre mulheres indígenas e ditadura militar brasileira está muito além de uma discussão somente sobre gênero. A questão central consiste em pensar essas mulheres como indivíduos colonizados e marginalizados pelo poder dominante" (SOUZA, 2018 p. 344). Ela ressalta que "está além do ser mulher, pois os recortes interseccionais perpassam gênero, raça e etnia. As mulheres indígenas são subjugadas por três tipos de opressão, como perceberemos ao longo da análise dos documentos" (SOUZA, 2018 p. 344). Ela observa que "na questão da subalternidade feminina, penso a marginalização dessa mulher no cenário da produção colonial dominado pelo homem branco, estrangeiro e heterossexual". Para ela "o ser mulher que se encara na discussão feminista europeia não integra essas mulheres indígenas como sujeitos violados, pois percebe apenas um coletivo homogêneo, noção que será duramente combatida pelos autores e autoras de estudo decolonial” (SOUZA, 2018 p. 344). A autora faz referência à violação de direitos:

Outra questão que me chama atenção na leitura do Relatório são as categorias usadas para caracterizar as violências de gênero, dentre elas: aliciamento, sedução, defloração, infelicitação, desrespeito, entre outras. Atentando para o contexto social e político da época e para o autor do documento, entende-se porquê questões graves são tratadas em termos tão amenos. É necessário que falemos de estupro, abusos, assédios de maneira a compreender o quão insidiosas foram as ações da ditadura sobre as mulheres indígenas. Faz-se preciso tratar de questões como etnocídio e genocídio, pautados em um projeto "desenvolvimentista" que extermina e massacra, sobretudo mulheres, de forma contínua (SOUZA, 2018 p. $350)$.

Na perspectiva de uma análise sobre a questão do "outro" a filósofa Judith Butler analisa a representação de sua humanização ou desumanização pela simbologia do rosto como invisibilização da história de vida precária no Dossiê "Diferenças e (Des)Igualdades"(2011) da Revista Contemporânea (UFSCar). Butler diz que "seria um erro pensar que apenas precisamos encontrar as imagens certas e verdadeiras e que, dessa maneira, certa realidade será exprimida. A realidade não é exprimida por aquilo que está representado no interior da imagem, mas sim por meio do desafio à representação que a realidade entrega" (BUTLER, 2011, p. 28). Ela sugere que "teríamos que interrogar a emergência e o desaparecimento do humano nos limites do que podemos saber, do que 
podemos ouvir, do que podemos ver, do que podemos sentir" e que isso poderia "nos instigar a, afetivamente, revigorar os projetos intelectuais da crítica, do questionamento, da tentativa de entender as dificuldades e demandas da tradução cultural e do dissenso" para "criar um senso do público no qual vozes de oposição não são temidas, degradadas ou descartadas, mas valorizadas pela instigação à democracia sensata que ocasionalmente realizam” (BUTLER, 2011, p. 32).

Espera-se com a pesquisa dar visibilidade e voz às mulheres indígenas e suas questões, principalmente com ações afirmativas que representem as relações atuais com a cultura e a tradição pela alimentação. A partir de uma análise conjuntural que apresenta o contexto das consequências do contato com a colonização a proposta é oportunizar reflexões sobre diversidade intrínseca aos grupos de habitam o território nacional. Na próxima sessão apresentaremos algumas questões ligadas à projetos de desenvolvimento dos grupos indígenas na atualidade.

\section{Etnodesenvolvimento e os grupos indígenas}

Ao falar sobre as relações entre europeus e Mbyá-Guarani na região Sul do Brasil, em meados do século XVI, Silvio Coelho dos Santos (2002, p. 88-89) diz que "foram os Carijó que passaram para os europeus, nesta parte da América, os saberes fundamentais à sua sobrevivência no espaço geográfico que estavam invadindo. Esses saberes chegaram até nós, absorvidos que foram pela população que acabou dominante". Para Santos (2002, p. 89) o nome Carijó foi dado pelos europeus para os Guarani que viviam no litoral Sul. Esse povo desfrutava de tudo o que a natureza oferecia. Com a prática da agricultura de subsistência "conheciam diferentes variedades de milho, de feijão, de mandioca e de abóbora, que cultivavam em pequenas roças de coivara. Plantavam ainda o algodão, o fumo, a cabaça e um número expressivo de plantas medicinais" (SANTOS, 2002, p. 88-89). Para o autor, a vinculação dos grupos indígenas com o território é uma condição pré-colombiana, onde cultura e tradição expressam "maneiras de sobrevivência que a humanidade logrou construir em sua trajetória no ecúmeno terrestre e assim depositários de especificidades biossócioculturais que impõem o respeito do estado brasileiro" (SANTOS, 1995, p. 105). Santos (1995, p. 104) ressalta que "as conquistas em questão foram frutos de séculos de resistência e de um forte movimento de lideranças indígenas e de suas organizações".

Para Cal y Major (2010, p. 67) “'la autonomía’ como paradigma, se encuentra en un proceso de construcción". Para Santos (1999, p. 272) “a ordem global e a ordem local constituem duas situações geneticamente opostas, ainda que em cada uma se verifiquem aspectos da outra. A razão 
universal é organizacional, a razão local é orgânica". O modelo de desenvolvimento ditado pelos países colonizadores e detentores do poder econômico é baseado até os dias atuais em processos coloniais de exploração das populações e do meio ambiente. Um exemplo é a construção de hidroelétricas e barragens nos territórios tradicionais (BRIGHENTI, 2015).

O Brasil, assim como outros países, necessita de alternativas, inclusive de formação e comunicação. Com a globalização, em pleno século XXI, diversos movimentos sociais e populares surgem com lutas que reafirmam identidades questionando o processo histórico de desenvolvimento e o papel do desenvolvimento regional. É uma parcela da população que se organiza para lutar pela justiça territorial, como os Mbyá-Guarani à procura da "Terra sem Mal" (CLASTRES, 1978). Com o meio ambiente alterado as florestas se tornam escassas, bem como o acesso aos recursos naturais. Essas questões envolvem diretamente os grupos indígenas, a sociedade envolvente e os processos de desenvolvimento.

O Vale do Rio Tijucas, local onde se estabeleceu o tekoá vy'a, passou por processos de exploração da madeira, plantação de cana de açúcar e fabricação de tijolos com barro em olarias. Grande parte dessa área foi afetada por esses ciclos baseados na exploração da natureza de maneira insustentável, modificando a paisagem. A partir da década de 1970 com a era do "progresso" no Brasil o território se modificou ainda mais com a urbanização e industrialização. Na agricultura, a inserção dos insumos químicos, agrotóxicos e sementes transgênicas incentivada por bancos em programas de crédito acelerou a modificação genética em larga escala alterando a relação tempo/natureza. Na década de 1990, muitas famílias de agricultores optaram pela "semente milagrosa". As famílias que não guardaram suas sementes e não conseguiram se manter na cadeia produtiva de um mercado altamente rentável, como foi publicizado pelo governo, passaram por processos de endividamento ou êxodo rural, migração para o trabalho em indústrias mantendo um cultivo de subsistência na propriedade ou plantando fumo. No caso da comunidade pesquisada Mbyá-Guarani vy’a em Major Gercino (SC) há uma preocupação com o seu entorno onde agricultores plantadores de fumo ocupam propriedades vizinhas, além da intensa produção de eucalipto para suprir as necessidades das empresas têxteis da região.

No tekoá vy’a há água limpa, mata (secundária ou terciária), roça, animais silvestres. Os moradores que pertencem à Terra Indígena (TI) já desenvolvem estratégias de manejo para a preservação do que ainda resta na mata, com práticas de caça, coleta e pesca reduzidas. Buscam a autonomia alimentar, mas atualmente sobrevivem também com a compra e doação de alimentos de maneira complementar. A partir do crescimento populacional indígena os Mbyá-Guarani já se 
preocupam com a demarcação de outras terras, medida essencial para que eles possam dar continuidade às suas práticas agrícolas e alimentares ditas “tradicionais”. Existem no tekoá vy’a tanto moradias tradicionais construídas por eles, feitas com barro bem como moradias de alvenaria que foram doadas pelo convênio com o governo. Estão previstos no convênio um posto de saúde e uma escola, mas que ainda não foram construídos. No tekoá vy'a existe uma opy, casa de reza, construída no centro do tekoá para que mulheres e crianças possam participar dos rituais à noite e levar os doentes quando necessário. Na parte de saúde, recebem visita de um agente ${ }^{7}$ municipal a cada quinze dias e aliam a medicina atual com os saberes do pagé, o líder espiritual.

Para o enfrentamento das desigualdades e a reivindicação de novas terras os Mbyá-Guarani se organizam em várias frentes de atuação: a comissão de caciques Nhemonguetá, Comissão Nacional de Terras Guarani Yvy Rupa, $1^{\circ}$ Encontro de Mulheres Mbyá-Guarani, grupos de estudantes, professores e jovens. Apresentaremos diagnósticos expostos por pesquisadores e suas sugestões na área do Desenvolvimento Regional em busca de autonomia nos processos de levantamento de dados, planejamento e execução de projetos que busquem entender as demandas locais, regionais e globais na atualidade.

O Relatório-Síntese da Avaliação Ecossitêmica do Milênio do programa das Nações Unidas para o Meio Ambiente (2005, p. 28-29) faz uma análise sobre o impacto das mudanças climáticas sobre as populações pobres, mulheres e povos nativos que não têm sido considerados de forma adequada nas decisões gerenciais, como a privatização do que antes constituíam recursos de acesso comum, as diferenças significativas entre funções e direitos entre os gêneros em muitas sociedades, a dependência de populações rurais dos serviços ecossistêmicos. O documento traz um estudo que sintetizou dados de 17 países e constatou que $22 \%$ da renda doméstica de comunidades campesinas em regiões florestadas provêm, em geral, de fontes não incluídas nas estatísticas nacionais, como a exploração de alimentos silvestres, madeira para combustível, forragem, plantas medicinais e madeira. Essas atividades formavam uma porção muito maior da renda total das famílias mais pobres do que das famílias mais abastadas, tendo essa renda especial importância dos períodos de escassez, previsível e imprevisível, de outras fontes de sustento (Relatório-Síntese da Avaliação Ecossistêmica do Milênio, 2005, p. 29). Nos projetos de desenvolvimento esses princípios podem ser aliados às ideias de Elinor Ostrom (2012) sobre o uso dos recursos de acesso comum, no qual ela ressalta que as abordagens governamentais de cima para baixo não funcionaram. Para ela muitas comunidades são capazes de desenvolver espontaneamente suas próprias abordagens para a gestão

\footnotetext{
${ }^{7}$ Os moradores da aldeia recebem visitas da Secretaria Especial de Saúde Indígena (Sesai).
} 
dos recursos de acesso comum e as comunidades são capazes de encontrar formas estáveis e eficazes para definir os limites de um recurso de acesso comum.

Fazendo referência aos saberes que ligam os povos originários aos seus territórios Barrenechea (2013, p. 58-59) apresenta em seu artigo uma série de encontros e eventos organizados em torno dos direitos das mulheres indígenas "muchas de las zonas o territorios habitados por indígenas son estratégicos por ser centros de diversidade de cultivos; em 1997, el 90\% de las tierras de mayor diversidad del planeta no tenían protección gubernamental sino que estaban al cuidado de los pueblos indígenas". Segundo a autora "para las poblaciones indígenas, la tierra y sus recursos naturales representan la única o la principal fuente de sobrevivencia” (BARRENECHEA, 2013, p. 59). Segundo ela "la mayoría de las mujeres rurales, y las indígenas em particular, trabajan la tierra y mantienen com ella uma relación estrecha” (BARRENECHEA, 2013, p. 60).

Stavenhagen (1985, p. 37) analisa algumas formas de como a "etnicidade se articula ao processo de desenvolvimento". Diz que "primeiro, é preciso determinar as circunstâncias históricas concretas em que surgem tais movimentos e como eles se relacionam com os conflitos sociais e econômicos mais amplos de seu tempo e lugar" (STAVENHAGEN, 1985, p. 38-39). "A etnicidade, a classe, a política e o estado-nação estão inextrincavelmente ligados. Existe aqui um grande espaço para a pesquisa básica". Segundo o autor, "os planejadores e políticos de todo o mundo têm que lidar com fatores étnicos no desenvolvimento. No entanto, muitos deles preferem ignorar o assunto, porque ele pode questionar as premissas do estado-nação" (STAVENHAGEN, 1985, p. 40). E reafirma: "proponho que o etnodesenvolvimento, isto é, o desenvolvimento de grupos étnicos no interior de sociedades mais amplas, deva tornar-se a principal questão da reflexão sobre o desenvolvimento, tanto teórica quanto praticamente" (STAVENHAGEN, 1985, p. 41). Segundo ele “o etnodesenvolvimento é concebido como um processo dinâmico e criativo que, mais do que limitá-las, pode liberar energias coletivas para o seu desenvolvimento" (STAVENHAGEN, 1985, p. 43).

Para Verdum (2002, p. 88) "o conceito de etnodesenvolvimento se formou então como um contraponto crítico e alternativo às teorias e ações desenvolvimentistas e etnocidas, que tomavam as sociedades indígenas e as comunidades tradicionais em geral como obstáculos ao desenvolvimento, à modernização e ao progresso". Para o autor "pode-se afirmar que a emergência das entidades indígenas e o crescimento de seu papel político no processo de democratização no Brasil estão relacionados a quatro fatores". Segundo ele esses fatores seriam a "necessidade de auto-organização voltada para a defesa de territórios, recursos naturais e autonomia política; o processo mais amplo 
de 'redemocratização' da sociedade nacional verificado nos anos 1980 [...] a crise do modelo tutelar gerido pelo Estado nacional; e o contexto transnacional" (VERDUM, 2002, p. 90). Azanha (2002, p. 32) diz que o "etnodesenvolvimento, quando referido às sociedades indígenas brasileiras, envolveria indicadores", tais como “a) aumento populacional, com segurança alimentar plenamente atingida; b) aumento do nível de escolaridade, na 'língua' ou no português, dos jovens aldeados; c) procura pelos bens dos 'brancos' plenamente satisfeita por meio de recursos próprios, gerados internamente de forma não predatória” e, por último, as decisões políticas como: “d) pleno domínio das relações com o Estado e agências de governo, a ponto de a sociedade indígena definir essas relações, impondo o modo como deverão ser estabelecidas" Para ele "esses pontos também podem ser tomados como as grandes linhas ou metas ideais de um projeto de etnodesenvolvimento sustentado para sociedades indígenas" (AZANHA, 2002, p. 32).

Fontoura, (2015, p. 136) em pesquisa intitulada "Direitos, desenvolvimento e povos indígenas: limites, possibilidades e desafios às políticas públicas na atualidade brasileira" afirma que "historicamente o processo de desenvolvimento nos países latinoamericanos esteve intrinsicamente ligado à consolidação do Estado Nacional, sob o qual o liberalismo, como aparato ideológico-político, sustentou as linhas pelas quais se definiram as relações sociais entre indígenas e não indígenas e o projeto modernizador" (FONSECA, 2016). Para ela, "hoje advém as complicações e constantes tensões em torno da demarcação das Terras Indígenas (TI), sendo que, mesmo com a resistência e luta destes povos, muitas foram demarcadas muito aquém de seu território original" (FONTOURA, 2015, p. 145). A autora faz referência ao "etnodesenvolvimento" como sendo "premissa do reconhecimento político dos povos indígenas dentro da esfera do Estado, é indispensável a restituição e garantia dos territórios étnicos como sendo território de um povo que se afirma como uma unidade social, jurídica e política, capaz de exercer decisões substantivas sobre seu território" (FONTOURA, 2015, p. 145).

À vista disto, para os povos indígenas, possibilitar construir seu futuro em consonância com suas experiências históricas e os recursos reais e potenciais de sua cultura como exercício da capacidade social em definir e guiar seu desenvolvimento apresenta-se como vias iminentes o planejamento e a instrumentalização de um programa de Etnodesenvolvimento. Meio que implica em transformar radicalmente o contexto social, econômico, político e ideológico da sociedade nacional que historicamente vem impossibilitando o florescimento de capacidades de ser e fazer aos povos indígenas e que somente poderá ser avaliado e dimensionado de acordo com as condições concretas de cada caso e, para tanto, por meio de um crescente processo de autonomia (FONTOURA, 2015, p. 150). 
Segundo Fontoura (2015, p. 158), no Brasil "as políticas públicas de Etnodesenvolvimento têm sido regidas por dois eixos: desenvolvimento sustentável indígena e segurança alimentar”. A autora faz críticas à atual política indigenista nacional dizendo que "os direitos sociais e de cidadão são substituídos por políticas assistencialistas como forma de amenizar os impactos da desigualdade sociais e os conflitos e tensões presentes nas lutas de resistência destes povos" (FONTOURA, 2015, p. 164). Ela acredita que a partir do diálogo intercultural "criam-se possibilidades históricas para a assunção de sujeitos de direitos, base para se construir uma convivência social onde a diferença e a igualdade possam se entender constituindo estratégias para enfrentar colonialidades ${ }^{8}$ " (FONTOURA, 2015, p. 173). Litaiff (2008) em estudo realizado na Terra Indígena Mbyá-Guarani Tekoa Marãgatu, município de Imaruí (SC) apresenta a experiência realizada para maior autonomia e auto-subsistência do grupo:

1. análise e correção do solo para melhor produtividade, respeitando, porém, os princípios da cultura guarani, que prevê a utilização preferencial da agricultura orgânica; 2. Plantio de milhares de mudas de árvores frutíferas (laranja-lima, goiaba, banana etc.); 3. aquisição de pequenos animais, como galinhas, patos e marrecos, principais fontes de proteína; 4. construção de açudes para criação de peixes (principalmente carpa e tilápia, de fácil manejo); 5. reflorestamento da mata no interior das áreas através do cultivo de milhares de mudas de árvores típicas da região, principalmente: palmeira, canela, cedro, pela sua importância cosmológica, quase totalmente desaparecidas nestes locais; 6 . a partir da concepção do manejo agroflorestal (SAF - Sistema Agroflorestal) guarani, identificação não só das espécies coletadas, como também do local e da técnica utilizada (que posteriormente teve classificação biológica, traçando paralelos com a taxionomia guarani); 7. incentivo à prática da roça tradicional (coivara), que constitui a base alimentar guarani, rica em amido (milho, mandioca, batata-doce, amendoim, feijão etc.); 8.geração de conhecimento teórico-prático que hoje orienta projetos nas áreas de Etnologia Indígena, Mitologia, Ecologia e Saúde (LITAIFF, 2008, p. 119-120).

Podemos encontrar projetos de desenvolvimento baseados no crescimento econômico que mantêm a pobreza, a má nutrição, a violência e as desigualdades. Propomos sob esse aspecto o modelo de desenvolvimento encontrado entre os grupos indígenas, priorizando o respeito entre os seres e a relação com os não-humanos e o meio ambiente, onde as relações de reciprocidade se oferecem como modelos a serem respeitados e preservados como também para refletirmos sobre o próprio desenvolvimento que vem se fazendo na nossa sociedade, contribuindo para a continuidade de práticas culturais em sua diversidade. Essa constitui a base do "Etnodesenvolvimento"

8 “A colonialidade é um dos elementos constitutivos e específicos do padrão mundial do poder capitalista. Sustenta-se na imposição de uma classificação racial/étnica da população do mundo como pedra angular do referido padrão de poder e opera em cada um dos planos, meios e dimensões, materiais e subjetivos, da existência social quotidiana e da escala societal. Origina-se e mundializa-se a partir da América” (QUIJANO, 2000, p. 73). 
(STAVENHAGEN, 1985). Pode-se também propiciar uma reflexão para se aperfeiçoar outros modelos de desenvolvimento tais como o "Não-Desenvolvimento" (THEIS, 2018), ou teorias como o "Ecodesenvolvimento" (SACHS,1993), "Decrescimento" (LATOUCHE, 2009), "Desenvolvimento Sustentável” (MAX-NEEF, 2012), "Ecossocioeconomia” (SAMPAIO; DALLABRIDA, 2009) e "Ecofeminismo" (WARREN,2000; MIES; SHIVA, 2007). São muitos os caminhos. Podemos acreditar em um possível futuro com mais acesso à diferentes direitos e à diversidade cultural, que tem se mostrado uma fonte de enriquecimento inesgotável para pensarmos a nossa própria sociedade.

\section{Considerações Finais}

A mulher indígena teve e tem um papel importante na conformação das Colônias e dos Estados Nacionais, tendo seu conhecimento sobre os alimentos e a alimentação, o seu trabalho e o seu corpo como base do desenvolvimento. A invisibilidade desse papel é um processo colonizador, patriarcal e capitalista. $O$ recorte de gênero onde a mulher arraigada ao território ressignifica sua história em uma perspectiva decolonial e reivindica seus direitos é parte do processo unificador pelo respeito à diversidade. $\mathrm{Na}$ atualidade ela tem um papel decisivo na questão da alimentação, na reprodução dos saberes e fazeres femininos no grupo, detém a maior responsabilidade sobre as crianças e a infância como forma de resistência face ao processo de colonização. É a reafirmação de sua identidade cultural.

Muitos dos saberes relacionados à culinária regional e nacional na atualidade foram incorporados dos grupos indígenas locais baseados em recursos encontrados na Mata Atlântica, o que tem contribuído decisivamente para o desenvolvimento local e regional até os dias atuais, sendo as mulheres as detentoras desse saber que vem sendo repassado de uma geração a outra (SILVA, $2003 ; 2008)$.

Os Mbyá-Guarani têm propostas alternativas de desenvolvimento, como todos os grupos indígenas e devemos ouvi-las para que proponham a sua própria visão de política de desenvolvimento local e regional. Cada grupo pode contribuir decisivamente para a continuidade de sua tradição com ações cotidianas, o que já está sendo praticado no tekoá vy'a de Major Gercino (SC). Eles estão permanentemente interessados e organizados ${ }^{9}$ para dar continuidade às suas práticas alimentares pela valorização de suas sementes "tradicionais", um patrimônio genético,

\footnotetext{
${ }^{9}$ Ver Comissão Nhemonguetá organização tradicional de Caciques e lideranças do Povo Indígena Guarani do litoral e Comissão Guarani Yvyrupa (CGY).
} 
mantido através da sua prática agrícola em suas terras. Eles buscam parceiros para fortalecer sua cultura e continuar a praticar no cotidiano suas atividades identitárias que reforçam o seu modo de ser Mbyá. Esses agricultores familiares trocaram informações e experiências desde o contato, influenciando a agricultura praticada hoje nas comunidades e no sistema alimentar vigente. Para o cacique Mbyá-Guarani da aldeia pesquisada werá mirim, Artur Benite, do tekoá vy'a em Major Gercino (SC) é necessário que a área seja produtiva, que se tenha o conhecimento sobre a plantação, sobre as sementes, as influências da lua e a água deve ser limpa.

Durante a pesquisa conversamos com três gerações de mulheres que puderam nos contar as mudanças e as permanências na alimentação da criança Mbyá-Guarani. Uma dessas mulheres pará mirim Cláudia Benite foi nomeada vice-cacique, o que demonstra seu papel de representatividade entre as mulheres na comunidade. A identidade do grupo Mbyá-Guarani e identificação do alimento, além do estudo de seu preparo é permeada pela questão de gênero que diferencia homens e mulheres.

\section{Referências}

ANDRADE, M. M. de; BELLINGER, C.. Alimentação nas escolas indígenas: desafios para incorporar práticas e saberes. Comissão Pró-Índio de São Paulo. São Paulo: 2016. Disponível via <http://www.cpisp.org.br/pdf/AlimentacaoNasEscolasIndigenas.pdf > Acesso em 24/06/2016.

AZANHA, G. Etnodesenvolvimento, mercado e mecanismos de fomento: possibilidades de desenvolvimento sustentado para as sociedades indígenas no Brasil. In: LIMA, A.C. S., BARROSO-HOFFMANN, M.(orgs.). Etnodesenvolvimento e Políticas Públicas: bases para uma nova política indigenista. Rio de Janeiro: Contra Capa Livraria/ LACED, 2002, p. 29-37. Disponível via 〈http://laced.etc.br/site/arquivos/02-Etnodesenvolvimento.pdf> Acesso em 03/03/2017.

BARRENECHEA, B. G. Mujeres indígenas: saberes ancestrales y reconocimiento de derechos. In: Identidades, resistencias e propuestas civilizatorias en América Latina. Departamento de Estudios Ibéricos y Latinoamericanos. Universidad de Guadalajara. Editorial Ciencias Sociales. La Habana, 2013. p. 57-74.

BRIGHENTI, C. A. Violência e desenvolvimento: o "desenvolvimento" versus os povos indígenas. Relatório Violência Contra os Povos Indígenas no Brasil. Le Monde Diplomatique Brasil, 2015. Disponível via <https://diplomatique.org.br/o-desenvolvimento-versus-os-povos-indigenas/> Acesso em 09/08/2018.

. Povos Indígenas em Santa Catarina. In: NÖTZOLD, A.L.V.; ROSA, H.A.; BRINGMANN, S.F.(orgs.). Etnohistória, história indígena e educação: contribuições ao debate. Editora Pallotti. Porto Alegre (RS) 2012. 
BUTLER, J. Vida precária. Contemporânea, São Carlos, v. 1, n. 1, p. 13-33, jan.-jun. 2011. Disponível em: 〈http://www.contemporanea.ufscar.br/index.php/contemporanea/article/view/18/3 >. $13 / 01 / 2019$.

CAL Y MAJOR, A.B. Autonomía: la emergencia de um paradigma em las luchas por la descolonización en América Latina. In: GONZÁLEZ, M.; CAL Y MAJOR, A.B., ORTIZ, P.O.(orgs.). La autonomía a debate: Autogobierno indígena y Estado plurinacional en América Latina. $\quad$ FLACSO. Quito.2010. Disponível via <https://www.iwgia.org/images/publications//0468_Libro_autonomia_a_debate_eb.pdf $>$ Acesso em 08/01/2018.

CLASTRES, H. Terra sem mal. São Paulo: Brasiliense, 1978.

DARELLA, M.D; GARLET, I.J.; ASSIS, V.S. Estudo de Impacto: as populações indígenas e a duplicação da BR 101, trecho Palhoça/SC - Osório/RS. Florianópolis - São Leopoldo, 2000. Disponível

via $<$ https://view.officeapps.live.com/op/view.aspx?src=http\%3A\%2F\%2Fwww.antropowatch.com. br\%2Fcariboost_files\%2FTX3_201_20eia-rima.doc> Acesso em 10/11/2014.

DÓRIA, C.A. A cozinha dos guaranis: de onde partiu a culinária caipira. A culinária caipira da Paulistânia. Ed. Três Estrelas, 2018.

FEDERICI, S.. Calibã e a bruxa: mulheres, corpo e acumulação primitiva. Tradução Coletivo Sycorax. Editora Elefante, 2017. Disponível via <http://coletivosycorax.org/wpcontent/uploads/2016/08/CALIBA_E_A_BRUXA_WEB.pdf> Acesso em 27/08/2017.

FERNANDES, F. A função social da guerra na sociedade tupinambá. Laraia. - São Paulo: Globo, 2006.

FERRARO, M. R. A caça comercial das perdizes (Rhynchotusrufescens) para abastecimento urbano (1860 -1938). Universidade estadual de Goiás - UEG/CCHSE. [Anais eletrônicos] 15 SEMINÁRIO NACIONAL DE HISTÓRIA DA CIÊNCIA E DA TECNOLOGIA.Florianópolis (SC), $2016 . \quad$ Disponível <http://www.15snhct.sbhc.org.br/resources/anais/12/1479121136_ARQUIVO_Ferraro_Perdiz_SB HC_2016_revisto.pdf $>$ Acesso em 24/08/2017.

FONSECA, L.G.D. Despatriarcalizar e decolonizar o Estado Brasileiro - um olhar pelas políticas públicas para mulheres indígenas. [Tese de Doutorado]. Programa de Pós-Graduação em Direito. Universidade de Brasília (UNB). Brasília, 2016. Disponível via <http://repositorio.unb.br/bitstream/10482/22132/1/2016_L\%C3\%ADviaGimenesDiasdaFonseca.p df> Acesso em 04/09/2017.

FONTOURA, G.C. Direitos, desenvolvimento e povos indígenas: limites, possibilidades e desafios às políticas públicas na atualidade brasileira. Dissertação de Mestrado]. PPGDR/FURB, $2015 . \quad$ Disponível via <http://www.bc.furb.br/docs/DS/2015/360539_1_1.pdf> Acesso em 27/08/2017. 
LADEIRA, M.I. Espaço geográfico Guarani-Mbyá: significação, constituição e uso. Maringá, PR: Eduem. São Paulo: Edusp, 2008.

LASMAR, C. Mulheres indígenas: representações. Revista Estudos Feministas, Florianópolis, v. 7, n. $\quad 1 \quad-2, \quad$ p. $143-156, \quad 1999 . \quad$ Disponível em: <https://periodicos.ufsc.br/index.php/ref/article/view/11989/11264>. Acesso em 05/08/2017.

LATOUCHE, S. Pequeno tratado do decrescimento sereno. São Paulo: Editora WMF, 2009.

LITAIFF, A. Sem tekoa não há teko, sem terra não há cultura: estudo e desenvolvimento autosustentável de comunidades indígenas guarani. UFSC/UNISUL. Espaço Ameríndio, Porto Alegre, v. 2, n. 2, p. 115-123, jul./dez. 2008. Disponível em <http://seer.ufrgs.br/EspacoAmerindio/article/download/6001/4567> Acesso em 28/10/2014.

LITAIFF, A., DARELLA, M.D.P. Os índios Guarani Mbyá e o Parque Estadual da Serra do Tabuleiro. XXII REUNIÃO BRASILEIRA DE ANTROPOLOGIA.Fórum de Pesquisa 3: "Conflitos Socioambientais e Unidades de Conservação". Brasília, 2000. Disponível via <http://www.antropowatch.com.br/os_indios_guarani_e_o_parque estadadual_daserra_do_tabuleiro.rtf $>$ Acesso em 27/08/2017.

MALINOWSKI, B. Um diário no sentido estrito do termo. Tradução de Celina Cavalcante Falck. -Rio de Janeiro: Record, 1997.

MAUSS, M. Ensaio sobre a dádiva: forma e razão da troca nas sociedades arcaicas. In: MAUS, M. Sociologia e antropologia. Tradução: Paulo Neves. São Paulo: Cosac \& Naify, 2003, p. 185-314.

MAX-NEEF, M.A. Desenvolvimento à escala humana: concepção, aplicação e reflexões posteriores. Contribuição de Antonio Elizalde e Martin Hopenhayn. Tradução Rede Viva. Blumenau: Edifurb, 2012.

MENDES, L. Mulheres Mbyá-Guarani - alguns apontamentos pré-campo. PPGA/UFF REUNIÓN DE ANTROPOLOGÍA DEL MERCOSUR - Uruguai, 2015 GT 117. Disponível via <http://xiram.com.uy/ponencias/GT-117/Luna\%20Mendes_\%20Mulheres\%20Mby\%C3\%A1Guarani.\%20Alguns\%20apontamentos\%20pr\%C3\%A9-campo.pdf> Acesso em 23/03/2018.

MIES, M.; SHIVA, V. Ecofeminismo - teoria, crítica y perspectivas. Mujeres, voces y propuestas. Barcelona: Icaria Antrazyt, $2007 . \quad$ Disponível via <http://www.icariaeditorial.com/pdf_libros/ecofeminismo.pdf > Acesso em 29/01/2019.

MONTEIRO, J.M. De índio a escravo: a transformação da população indígena de São Paulo no século XVII. Revista de Antropologia. São Paulo, 1989, p. 151-174.

OLIVIER DE SARDAN, J. Anthropologie et développement: essaien socio-anthropologie du changement social. Marseille: APAD; Paris, Karthala, Éditeur, 1995. Collection: Hommes et sociétés. Disponível via $<$ http://classiques.uqac.ca/contemporains/olivier_de_sardan_jean_pierre/anthropologie_et_de veloppement/anthropo_et_developpement.pdf> Acesso em 29/04/2016. 
ORGANIZAÇÃO DAS NAÇÕES UNIDAS - ONU/BR Glossário de termos do Objetivo de Desenvolvimento Sustentável 5: Alcançar a igualdade de gênero e empoderar todas as mulheres e meninas, 2016. Disponível via <https://nacoesunidas.org/wpcontent/uploads/2017/06/Glossario-ODS-5.pdf> Acesso em 06/03/2019.

OSTROM, E. The future of the commons: beyond market failure and government regulations. London: The Institute of Economic Affairs, 2012.Disponível via < https://iea.org.uk/wpcontent/uploads/2016/07/IEA\%20Future\%20of\%20the\%20Commons\%20web\%20291.10.12.pdf $>$ Acesso em 03/09/2017.

QUIJANO, A. Colonialidade do poder e classificação social. In: SANTOS, B. S.; MENESES, M.P.(orgs.). Epistemologia do Sul, 1940, p. 73-117.

RELATÓRIO-SÍNTESE DA AVALIAÇÃO ECOSSITÊMICA DO MILÊNIO (ONU) 2005. Disponível via <https://www.millenniumassessment.org/documents/document.446.aspx.pdf> Acesso em 20/05/2017.

ROULET, F. La Resistência de los Guarani del Paraguay a la Conquista Española (15971556). Editora Universitátia. Misiones, 1993.

SACHS, I. Estratégias de Transição para o Século XXI, desenvolvimento e meio ambiente. São Paulo: Studio Nobel, 1993.

SALOMONE, A.N. Mujeres e ideas en América Latina: una relación problemática. CUYO, Anuario de Filosofía Argentina y Americana, No 13, Año 1996, ISSN No 0590-4595, p.143-149.

SAMPAIO, C.A.C.; DALLABRIDA, I.S. Ecossocioeconomia das organizações: gestão que privilegia uma outra economia. Revista. FAE, Curitiba, v.12, n.2, p.17-33, jul./dez. 2009.

SANTOS, M. A natureza do espaço: técnica e tempo; razão e emoção. $3^{\text {a }}$ edição. São Paulo: Hucitec, 1999.

SANTOS, S.C. "Notas sobre a presença indígena na Ilha de Santa Catarina". In: PEREIRA, N. V.et al. (orgs.). A Ilha de Santa Catarina: espaço, tempo e gente. Florianópolis: Instituto Histórico e Geográfico de Santa Catarina, 2002.

Os direitos dos indígenas no Brasil. In: SILVA, A.L.; GRUPIONI, L.D.B.(orgs.).A temática Indígena na escola: novos subsídios para professores de $1^{\circ}$. E $2^{\circ}$. graus. Brasília: MEC/ MARI/ UNESCO, 1995, p. 87-108.

SCOTT, J. Gênero: uma categoria útil de análise histórica. Revista Educação e Realidade. v.15, n.2. Porto Alegre: 1995, p. 5-22. Disponível em <http://www.direito.mppr.mp.br/arquivos/File/SCOTTJoanGenero.pdf > Acesso em 14/10/2014.

SMITH, A. A violência sexual como uma ferramenta de genocídio. Espaço Ameríndio, Porto Alegre, v. $8, \quad$ n. $1, \quad$ p. 195-230, 2014. Disponível em: 
<http://seer.ufrgs.br/index.php/EspacoAmerindio/article/view/47357/29960>. $13 / 01 / 2019$.

SILVA, M. C. G. O papel da mulher no processo de adaptação alimentar dos imigrantes europeus em Blumenau. FAZENDO GÊNERO 8. Corpo, Violência e Poder. Florianópolis: 2008. Disponível em

<http://www.fazendogenero.ufsc.br/8/sts/ST6/Marilda_Checcucci_Goncalves_da_Silva_06.pdf $>$. Acesso em 27/10/2014.

A Alimentação e a Culinária de Imigração Europeia no Vale do Itajaí. Blumenau/Edifurb, Revista de Divulgação Cultural O Humano. No. 80 - maio/agosto de 2003.

SOUSA, E. L. Laudinhos antropológicos: as crianças indígenas e os processos de demarcação de terra. Revista Tellus, Campo Grande, MS, ano 18, n. 35, p. 113-138, jan./abr. 2018. Disponível via <http://www.tellus.ucdb.br/index.php/tellus/article/view/490> Acesso em 09/08/2018.

STAVENHAGEN, R. Etnodesenvolvimento: Uma Dimensão Ignorada no Pensamento Desenvolvimentista. Anuário Antropológico.vol. 84, 1985, p. 11-44. Disponível em $<$ http://www.google.com.br/url?sa=t\&rct=j\&q=\&esrc=s\&source=web\&cd=1\&ved=0CB8QFjAA\& url=http $\% 3 \mathrm{~A} \% 2 \mathrm{~F} \% 2 \mathrm{Fwww}$. dan.unb.br\%2Fimages $\% 2 \mathrm{Fpdf} \% 2 \mathrm{Fanuario}$ antropologico $\% 2 \mathrm{FSeparata}$ s1984\%2Fanuario84_rodolfostavenhagen.pdf\&ei=wSVOVK7oGs2MNsz9gPgI\&usg=AFQjCNGe Nf9_-bODOrpbAxPg9tmlfQV6BQ> Acesso em 01/08/2014.

TEMPASS, M.C. “Quanto mais doce, melhor": Um estudo antropológico das práticas alimentares da doce sociedade Mbyá-Guarani. [Tese de Doutorado]. Orientador: Prof. Dr. Sergio Baptista da Silva. Programa de Pós-Graduação em Antropologia Social. Instituto de Filosofia e Ciências Humanas. Universidade Federal do Rio Grande do Sul. Porto Alegre: fevereiro de 2010. Disponível em <http://www.bibliotecadigital.ufrgs.br/da.php?nrb=000748441\&loc=2010\&l=9a05df39af9a9caf $>$ Acesso em 18/03/2013.

THOMPSON, P. A voz do passado - História Oral. 2 ed. Paz e Terra. 1998.

VIVEIRO DE CASTRO, E. O perspectivismo ameríndio ou a natureza em pessoa. Ciência \& Ambiente. UFSM. v. 1, n.1, jul. 1990, p.123-132.

VERDUM, R. Etnodesenvolvimento e mecanismos de fomento do desenvolvimento dos povos indígenas: a contribuição do subprograma Projetos Demonstrativos (PDA). In: LIMA, A.C.S., BARROSO-HOFFMANN, M. (orgs.). Etnodesenvolvimento e Políticas Públicas: bases para uma nova política indigenista. Rio de Janeiro: Contra Capa Livraria/ LACED, 2002, p. 29-37. Disponível via <http://laced.etc.br/site/arquivos/02-Etnodesenvolvimento.pdf> Acesso em 03/03/2017.

WARREN, K. Ecofeminist Philosophy: A Western Perspective on What It Is and Why It Matters. Rowman \& Littlefield Publishers, 2000.

Artigo recebido em 20/04/2019. Aceito para publicação em 17/07/2019. 